Case Report

\title{
Cerebellar Infarction Associated with a Patent Foramen Ovale Revealed by Wallenberg Syndrome During a Migraine Attack
}

\author{
Soumaila Boubacar ${ }^{1, ~ *}$, Ngor Side Diagne ${ }^{1}$, Djibrilla Wazir Ben Adji , \\ Eric Gueumekane Bila Lamou ${ }^{1}$, Christian Madjirabe Ngarndiguina ${ }^{1}$, Youssoufa Maiga ${ }^{3}$, \\ Lala Bouna Seck ${ }^{1}$, Kamadore Touré ${ }^{1}$, Moustapha Ndiaye ${ }^{1}$, Amadou Gallo Diop ${ }^{1}$, \\ Mouhamadou Mansour Ndiaye ${ }^{1}$ \\ ${ }^{1}$ Department of Neurology, Fann National Teaching Hospital, Dakar, Senegal \\ ${ }^{2}$ Department of Medicine, National Hospital, Niamey, Niger \\ ${ }^{3}$ Department of Neurology, Gabriel Touré University Hospital, Bamako, Mali
}

Email address:

abounadjma@yahoo.fr (S. Boubacar)

${ }^{*}$ Corresponding author

\section{To cite this article:}

Soumaila Boubacar, Ngor Side Diagne, Djibrilla Wazir Ben Adji, Eric Gueumekane Bila Lamou, Christian Madjirabe Ngarndiguina, Youssoufa Maiga, Lala Bouna Seck, Kamadore Touré, Moustapha Ndiaye, Amadou Gallo Diop, Mouhamadou Mansour Ndiaye. Cerebellar Infarction Associated with a Patent Foramen Ovale Revealed by Wallenberg Syndrome During a Migraine Attack. American Journal of Psychiatry and Neuroscience. Vol. 4, No. 5, 2016, pp. 76-78. doi: 10.11648/j.ajpn.20160405.12

Received: August 3, 2016; Accepted: August 15, 2016; Published: September 7, 2016

\begin{abstract}
The occurrence of cerebellar infarction associated with a patent foramen ovale during a migraine attack is rare and ambiguous etiopathogenic explanation. We report the case of a young patient. It was about a 25 -years-old, migraine known since age of 8 years, with no particular medical history, admitted to the neurology department of Fann National Teaching Hospital of Dakar for headaches, acute onset of balance and walking disorders in a context of big rotatory dizziness. Neurological examination have objectified a Wallenberg syndrome. The rest of the physical examination was normal. The diagnosis of cerebellar infarction was retained on basis of brain CT and brain MRI. The etiologic test showed patent foramen oval at transoesophageal echocardiography. The diagnosis of migrainous infarction was retained on basis of the young age of the patient, migraine with aura, presence of patent foramen ovale (vascular risk factor etiology?) and lack of any other cause. Patient received anticoagulants and analgesics combined with physical rehabilitation. Outcome was favorable marked by motor recovery. A migrainous infarction, especially cerebellar infarction should be discussed in front of any attack in known migraine with focal neurological signs.
\end{abstract}

Keywords: Infarction, Migraine, PFO, Dakar, Senegal

\section{Introduction}

Occurrence of a cerebellar infarction associated with a patent foramen ovale (PFO) during a migraine attack is rare and ambiguous etiopathogenic explanation.

We report a recent cerebellum infarct case in a young Senegalese man with a patent foramen ovale.

\section{Case Report}

It was a 25 years old patient, migraine known since the age of 8 years, with no particular medical history, admitted in the neurology department of Fann National Teaching Hospital of Dakar (Senegal, West Africa) for headaches, balance and walking disorders with acute onset in a context of rotary dizziness. Neurological examination was objectified a static 
and kinetic cerebellar syndrome, right Claude Bernard Horner's syndrome, a right vestibular syndrome and spinothalamic syndrome of the left side of the body, all making a Wallenberg syndrome. The rest of the physical examination was normal. The diagnosis of cerebellar infarction was retained on basis of brain CT (Fig. 1) and brain MRI (Fig. 2) were respectively showed, ischemic injury in the right cerebellar hemisphere and hyperintensity in the posterior inferior cerebellar artery territory (PICA). The etiologic tests showed patent foramen oval at transesophageal echocardiography, the rest of complementary exams (electrocardiogram, echocardiography, ultrasound of the supra-aortic arteries, MRI angiography) was normal. The risk factors assessments were normal. The diagnosis of migrainous infarction was retained on basis of the young age of patient, migraine with aura, presence of a patent foramen ovale (vascular risk factor etiology?) and absence of any other cause. The patient received medical treatment with LMWH followed by AVK (Acenocoumarol), analgesics associated with a physical reeducation. The outcome was favorable with regression of balance disorders, decreasing of sustentation's polygon, a disappearance of dizziness and headache.

\section{Discussion}

The PFO is persistence after birth, a Most often asymptomatic aperture between the right atrium and the left atrium. PFO is present in a quarter of the population, without gender differences. [14]. The reason for the non PFO closure after birth in $25 \%$ of the population is unknown [9]. Migraine is a primary headache characterized by recurrent attacks which typically starts before age 40 . Migraine is a genetic disorder linked to chromosome 8 manifesting as seizures and idiopathic recurrent headaches $[3,8,10]$. The prevalence is $12 \%$ with feminine predominance of $2-3 / 1$ [14, 15]. Migraine is an independent risk factor for cerebral ischemia with an increased relative risk by a factor of $2[6,7]$. This vascular risk of migraine has been established for nearly 20 years. [7] Migraine infarction is rare and represents $0.5 \% 3.3 \%$ of cerebral infarction [13]. They require that a patient with a history of MA has for that patient, typical aura, persisting for $>60$ minutes and with neuroimaging signs of an infarct in a relevant area and provided that the stroke is not attributed to another disorder [17].

Otherwise, the epidemiological studies suggest bidirectional link between patent foramen ovale (PFO) and migraine with aura (MA) with a relative risk of 2 to have a PFO in the event of MA and have a MA in the event of PFO. There is no evidence link between PFO and migraine without aura (MSA) [14]. Our patient, in addition to migraine with aura, he carries patent foramen ovale. The diagnosis of PFO is based on various investigations highlighting the right-left shunt. The most sensitive is transesophageal ultrasound that can measure size of foramen and detect presence of aneurysm of the inter-atrial septum (ASIA) associated [11].

Our patient is a 25 years old, migraine patient known since the age of 8 years. He received a transesophageal echocardiography which allowed to objectify the PFO. Although inconstantly demonstrated, this statistical association between PFO and cryptogenic cerebral infarction in young patients was interpreted as causal and related to the occurrence of paradoxical embolism. However visualization of a thrombus through the FOP is rare [20]. Other mechanisms are possible such as cardiac arrhythmia associated [4] so that it is still unclear about the best secondary prevention in young patients with a PFO and brain infarction without other cause identified [14]. Some studies have difficulties in recruitment related to the multiplication of closures out protocol [11].

Any underlying cause (paradoxical embolism, heart arrhythmia) was detected in our patient. However, it was a patient having migraine with aura presenting with concomitant migraine its episode of Cerebellar infarction.

Cerebellar infarction may arise during a migraine with aura if the decline of cerebral blood flow accompanying propagated cortical depression reached, for unknown reasons, the ischemic threshold. In many reported cases, venous thrombosis was observed $[1,21]$, other hypotheses have been proposed, one of them based on the observation of a statistically significant relationship between stroke and interatrial septal abnormalities (PFO with aneurysm of the interatrial septum [16]. This suggests an in situ thrombus formation, even within a septal aneurysm [19]. Such infarction, qualified migraine infarction, essentially concerns the occipital cortex [14]. Several of these territories occipital infarction PICA have been described in the literature [12].

Cerebellar infarction in our patient has occipital topography due to occlusion of the PICA. Regarding management, the embolic stroke, paradoxical embolus by PFO, has long been a subject of controversy between interventional cardiologists and neurologists reserved because three prospective studies had concluded the uselessness of atrial septal occlusion [2]. However, since the end of 2013 where two multicenter studies with meta-analysis: one French [5] including 1224 patients versus 1226 medically treated controls and other US [18] on 1150 treated patients versus 1143 witnesses after randomized led to same conclusions. Recent studies provide statistical evidence of efficacy of percutaneous closure of PFO with a reduction of about one third of the risk of recurrence. However a slightly increased risk of atrial fibrillation was objectified in both studies, the consequences are not insignificant [2].

The PFO in our patient was not closed but medical treatment with anticoagulants has been administered for secondary prevention associated with analgesic treatment and physical rehabilitation. The outcome was favorable marked by motor recovery and regression of vestibule-cochlear signs.

\section{Conclusion}

Migrainous infarction especially cerebellar infarction should be discussed in front of any attack in known migraine with focal neurological signs associated. 


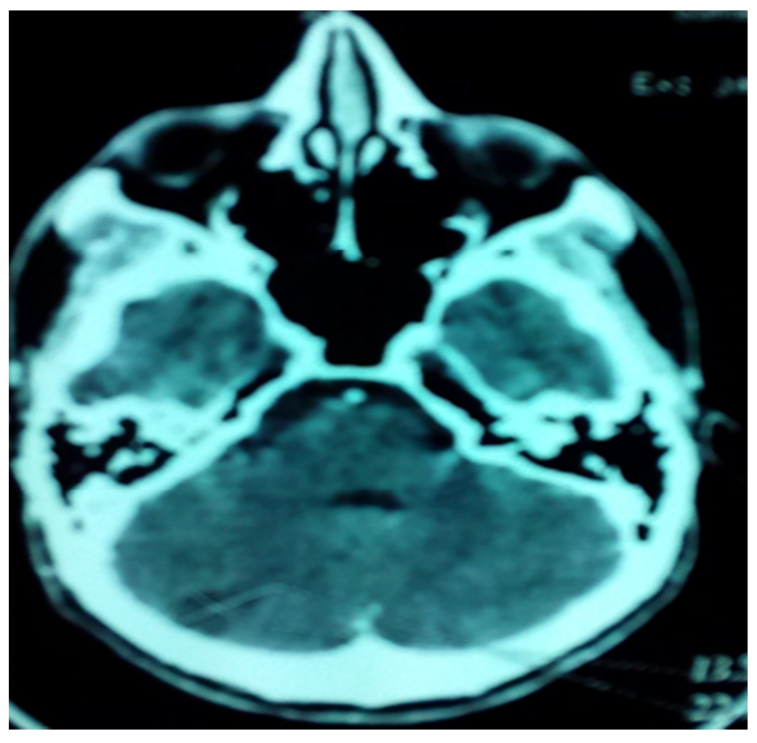

Fig. 1. Brain CT: Ischemic injury in the right cerebellar hemisphere.

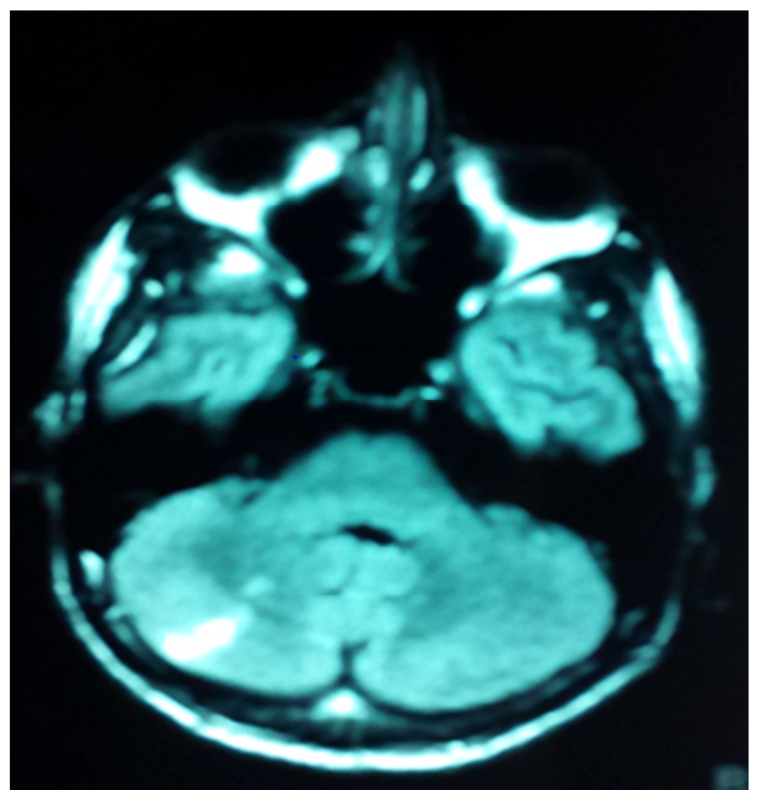

Fig. 2. Brain MRI: Hyperintensity in the posterior inferior cerebellar artery territory (PICA).

\section{References}

[1] Aboyans V, Lacroix P, Ostyn E, Cornu E, Laskar M. Diagnosis and management of entrapped embolus through a patent foramen oval. Eur J Cardiothorac Surg 1998; 14 (6): 624-8.

[2] AVC: Nouveautés thérapeutiques. (2015) Pierre Godeau P 14.

[3] BARON J. C, HAMON M. ET LAUNAY J. M. Physiopathologie. In: La migraine: Connaissances descriptives, traitements et prévention. Ed: Expertise Collective INSERM, Les Editions Inserm, Paris, 1998.

[4] BERTHET K, LAVERGNE T, COHEN A et al. (2000). Signifiant association of atrial vulnerability with atrial septal abnormalities in young patients with ischemic stroke of unknown cause. Stroke, 31: 398-403.
[5] Beygui F, Labombarda F, Sabatier R, et al. A meta-analysis of randomized trials comparing percutaneous closure of patent foramen oval to medical therapy. ESC congrès 2013; abstract 90273.

[6] C Lucas Migraine et dissections artérielles cervicales. Rev Neurol (Paris) 2005; 161: 6-7, 703-705.

[7] E. Guegan-Massardier, C. Lucas. Migraine et risque vasculaire. revue neurologique 169 (2013) 397-405.

[8] EL AMRANI M ET MASSIOU H. Migraine: aspects cliniques et traitements. Encycl Méd chir (Elsevier), Neurologie, 17-023-A-50, 1998, 7 p.

[9] HAERTER K, AYATA C, MOSKOWITZ MA. (2005). Cortical spreading depression: a model for understanding migraine biology and future drug targets. Headache Currents, 2: 97-103

[10] HEADACHE CLASSIFICATION COMMITTEE OF THE INTERNATIONAL HEADACHE SOCIETY. Classification and diagnostic criteria for headache disorders, cranial neuralgias, and facial pain. Cephalalgia 1988; 8 (suppl 7): 1-96

[11] HOMMA S, SACCO RL. (2005). Patent foramen ovale and stroke. Circulation, 112: 1063-1072.

[12] Kumral E, Kisabay A, Ataç C, Calli C, Yunten N. Spectrum of the posterior inferior cerebellar artery territory infarcts. Clinical-diffusion-weighted imaging correlates. Cerebrovasc Dis. 2005 ; 20 (5): 370-80.

[13] Kurth T, Diener HC. Migraine and stroke: perspectives for stroke physicians. Stroke 2012 b; 43: 3421-6.

[14] M. G. Bousser. Foramen ovale perméable et Migraine. Rev Neurol (Paris) 2007; 163: 1, 17-25.

[15] MAIGA Youssoufa, BOUBACAR Soumaïla, KANIKOMO Drissa, CISSOKO Yacouba, DIAKITE Sara, CISSOKO Lala, TESTA Jean, DIAGANA Mohamadou, ALOUS AG Mohamed, ATRAORE Hamar. La migraine en milieu scolaire dans la commune urbaine de Gao au Mali. Afr J Neurol Sci 2011; 30 (2): 49-55.

[16] Mas JL, Arquizan C, Lamy C, et al. Recurrent cerebrovascular events associated with patent foramen oval, atrial septal aneurysm, or both. N Engl J Med 2001; 345 (24): 1740-6.

[17] Olesen J, Bousser M-G, Diener H, Dodick D, First M, Goadsby P, et al. The International Classification of Headache Disorders: II Edition. Cephalalgia. 2004; 24 (suppl 1): 9-160.

[18] Renfigo-Moreno P, et al. Patent foramen ovale transcatheter closure vs. medical therapy on recurrent vascular events: a systematic review a, d meta-analysis of randomized controlled trials. Eur Heart J 2013; 34: 3342-52.

[19] Schneider B, Hanrath P, Vogel P, Meinertz T. Improved morphologic characterization of atrial septal aneurysm by transesophageal echocardiography: relation to cerebrovascular events. J Am Coll Cardiol 1990; 16 (4): 1000-9.

[20] SCHREITER SW, PHILLIPS JH. (1994). Thromboembolus traversing a patent foramen ovale: resolution with anticoagulation. J Am Soc Echocardiogr, 7: 659-662.

[21] Watanabe N, Akasaka T, Yoshida K. Large thrombus entrapped in apatent foramen oval of the atrial septum, which apparently "disappeared" without embolic events. Heart 2002; 88 (5): 474. 